\title{
DECISÃO JUDICIAL, ESTADO DEMOCRÁTICO DE DIREITO E INTERESSES ECONÔMICOS: UMA ANÁLISE DA RELAÇÃO ENTRE DIREITO E ECONOMIA A PARTIR DO CASO DA ADI 5624
}

\author{
JUDICIAL DECISION, DEMOCRATIC RULE OF LAW AND ECONOMIC \\ INTERESTS: AN ANALYSIS OF THE RELATIONSHIP BETWEEN LAW AND
}

ECONOMICS THROUGH THE CASE OF ADI 5624

\section{Letícia Tres Silvestri ${ }^{1}$ \\ Clarissa Tassinari ${ }^{2}$}

\begin{abstract}
RESUMO: O presente trabalho, tomando como ponto de partida a ideia de predadores do Direito (Streck), investiga a influência de interesses econômicos nas decisões judiciais. Como decisões judiciais fundamentadas em argumentos vinculados ao viés pragmatista da Análise Econômica do Direito (AED) podem representar uma ameaça ao Estado Democrático de Direito constituído sob as bases de uma Constituição compromissória? Este é o problema de pesquisa que o texto enfrenta. Para realizar a análise proposta, são discutidos os argumentos pragmatistas que constituem a fundamentação dos votos dos Ministros do STF exarados no julgamento da ADI 5.624. A escolha desse caso se justifica, sobretudo, por se tratar de uma decisão que tem como tema a constitucionalidade da Lei $\mathrm{n}^{\circ} 13.303$ de 2016 - conhecida como Lei das Estatais -, cujos impactos se dão essencialmente nas esferas política e econômica. Sugere-se, com base na Crítica Hermenêutica do Direito de Streck, que os interesses econômicos põem em risco o compromisso da decisão judicial com a manutenção da integridade e da coerência que asseguram a responsabilidade política do julgador na efetivação da democracia.
\end{abstract}

Palavras-chave: Decisão Judicial; Análise Econômica do Direito; Pragmatismo; Estado Democrático de Direito.

ABSTRACT: The present work, taking as a starting point the idea of Law predators (Streck),

\footnotetext{
${ }^{1}$ Mestranda em Direito pelo PPG Direito Unisinos/RS com bolsa CAPES/PROEX, Bacharela em Ciências Jurídicas e Sociais pela UFRGS; Unisinos, São Lepoldo/RS. E-mail: leticia3silvestri@gmail.com. Lattes: http://lattes.cnpq.br/7937071521462992. ORCID: https://orcid.org/0000-0003-1205-3479.

2 Pós-doutora em Direito (PPG Direito Unisinos/RS, com bolsa CAPES-PNPD), Doutora e mestre em Direito (PPG Direito da Unisinos/RS, com bolsas CNPq), Professora do Programa de PósGraduação em Direito (Mestrado e Doutorado) e da Graduação em Direito da Unisinos/RS, Coordenadora do grupo de pesquisa GPolis - Direito, Política e Diálogos institucionais, Advogada; Unisinos, São Leopoldo/RS. E-mail: clarissa@tassinari.adv.br. Lattes: http://lattes.cnpq.br/5065376917812503. ORCID: https://orcid.org/0000-0002-4437-9556.
} 
proposes to investigate the influence of economic interests in judicial decisions. How can judicial decisions based on arguments linked to the pragmatic bias of Economic Analysis of Law (EAL) may represent a threat to the Democratic Rule of Law founded on a compromissory Constitution? This is the research problem that the text aims to address. In order to carry out the proposed analysis, the pragmatist arguments that formed the basis for the votes of the STF Judges expressed in the judgment of ADI 5.624 will be discussed. The choice of this case is justified mostly because it is a judicial decision that has as its theme the constitutionality of Law $n^{0} 13.303$ of 2016, known as the State-Owned Law, whose impacts are essentially in the political and economic spheres. It is suggested, based on the Streck's Hermeneutic Criticism of Law, that economic interests put at risk the commitment of the judicial decision with the maintenance of integrity and coherence that ensure the political responsibility of the judge in the effectuation of democracy.

Keywords: Judicial decision; Economic Analysis of Law; Pragmatism; Democratic Rule of Law.

Sumário: 1. Introdução; 2. Análise Econômica do Direito (AED) e o pragmatismo jurídico segundo Richard Posner; 3. O caso da Medida Cautelar na ADI 5.624 e os argumentos político-econômicos do STF; 4. O papel do Poder Judiciário na defesa da Constituição segundo a Crítica Hermenêutica do Direito de Lenio Streck; 5. Considerações finais; 6. Referências.

\section{INTRODUÇÃO}

O presente artigo toma como ponto de reflexão inicial a concepção de predadores do Direito - a política, a moral e a economia -, que foram assim definidos pelo professor Lenio Streck:

\footnotetext{
O castelo erigido com o auxílio da política, da moral e da economia deve ser protegido dos predadores. A cavalaria da moral, a artilharia da política e a aviação da economia atacam, e devemos enfrentá-los com snipers epistêmicos. Direito é um fenômeno complexo. É atacado de fora e de dentro. (...) Uma derrota significa fragilização do direito e, por vezes, fim da própria democracia (RODAS, 2019, s.p.).
}

Não é novidade que as decisões judiciais são alvo de pressões políticas, midiáticas e religiosas, assim como de interesses econômicos. O Poder Judiciário não está imune à complexidade das relações que se estabelecem em nossa sociedade. No entanto, a racionalidade jurídica e a autonomia do Direito vêm sendo cada vez mais ameaçadas diante da adoção de racionalidades instrumentais, isto é, de juízos de valor tomados a partir de argumentos políticos, econômicos e morais (STRECK, 2019b, s.p.). 
Nesse cenário, e a partir da ideia de predadores do Direito, este trabalho busca investigar mais detidamente a influência de interesses econômicos nas decisões judiciais. Propomo-nos a avaliar como decisões judiciais fundamentadas em argumentos vinculados ao viés pragmatista da Análise Econômica do Direito (AED) podem representar uma ameaça ao Estado Democrático de Direito. Partimos do pressuposto de que o Estado Democrático de Direito está constituído sob as bases de uma "Constituição compromissória que consagra textualmente a cooriginariedade entre Direito e moral" (STRECK, 2017, p.226).

Para dar conta da investigação proposta, o presente artigo foi dividido em três momentos. Na primeira parte, realizamos uma síntese das principais características da Análise Econômica do Direito. Posteriormente, verificamos de que forma a AED pretende dar subsídios para a fundamentação das decisões judiciais, utilizando como material de análise os argumentos político-econômicos retirados dos votos dos Ministros do Supremo Tribunal Federal (STF) no caso da ADI 5624. Por fim, discorremos sobre o papel do Poder Judiciário na defesa da Constituição a partir das formulações de Lenio Streck em sua Crítica Hermenêutica do Direito, analisando como interesses econômicos podem representar uma ameaça ao Estado Democrático de Direito.

\section{ANÁLISE ECONÔMICA DO DIREITO (AED) E O PRAGMATISMO JURÍDICO SEGUNDO RICHARD POSNER}

Surgida nos Estados Unidos na década de 60, a Análise Econômica do Direito se desenvolveu, primordialmente, a partir de três pilares teóricos que retomaremos ao longo desta seção: o realismo jurídico estadunidense, o pragmatismo filosófico e o "utilitarismo tingido de consequencialismo" (MILLARD e HEINEM, 2018, p.279). Além disso, possui influência das ideias de importantes teóricos, como Thomas Hobbes, David Hume, Adam Smith e Jeremy Bentham (MARTINS, 2017, s.p.).

Em relação ao realismo jurídico, a versão estadunidense que influenciou a AED surgiu na primeira metade do século XX e tem Oliver Wendel Holmes como seu principal representante. Em apertada síntese, os adeptos do realismo jurídico estadunidense entendem que os magistrados exercem uma atividade criativa sobre o Direito e focam sua atenção não no caráter estático da realidade jurídica, mas nas mudanças, na observação dos fatos sociais 
a partir de uma atitude científica (HOLMES, 2007, p.336). Em consequência, concebem o direito como um meio para se atingir determinados objetivos sociais, criticam os conceitos jurídicos tradicionais e negam que o principal objeto de análise da Ciência do Direito seja o conjunto de regras jurídicas (STRECK, 2017, p.245).

Ainda que se subdivida em diversas correntes de pensamento, podemos afirmar que o principal expoente da Análise Econômica do Direito é o professor de Direito estadunidense Richard A. Posner, responsável por publicar, em 1973, a obra que sintetizou e aplicou de maneira acessível os fundamentos da microeconomia ao ensino do Direito ${ }^{3}$. Nos anos seguintes à publicação da referida obra, intitulada Economic analysis of law, o estudo da Análise Econômica do Direito rapidamente se disseminou entre as Faculdades de Direito estadunidenses, o que levou à elaboração de diversos textos de Análise Econômica do Direito voltados especificamente para o ensino do Direito e de forma a abranger todas as áreas do Direito (MACKAAY e ROUSSEAU, 2015, p.11).

A partir da metade da década de 70, o movimento da Análise Econômica do Direito também ganhou adeptos fora dos Estados Unidos, principalmente na Austrália, Canadá, Inglaterra e Suécia. Ao mesmo tempo, dentro do cenário estadunidense, Posner e os defensores da AED passaram a enfrentar críticas de juristas das mais diversas correntes, desde jusnaturalistas, filósofos, liberais, assim como de economicistas de perfil neoclássico e da escola austríaca. Os críticos questionavam se a Análise Econômica do Direito poderia ser considerada efetivamente uma teoria do Direito, o que colocou no centro do debate compreender "se a atribuição de direitos pode ser deduzida de considerações de eficácia ou se é necessário, para precisar a noção de eficácia, fixar previamente, ao menos, certos direitos fundamentais" (MACKAAY e ROUSSEAU, 2015, p.12 e 16).

Posner defende a primeira posição, aproximando-se, assim, dos pressupostos utilitaristas - corrente mencionada anteriormente como um dos principais pilares teóricos da AED. Em outras palavras, o autor entende que o ganho de uma maioria em detrimento da perda de uma minoria justificaria a ideia de uma atribuição de direitos baseada em

\footnotetext{
${ }^{3}$ Além de Posner, também foram importantes precursores da Análise Econômica do Direito os professores Ronald H. Coase (Universidade de Chicago), com a publicação de The Problem of Social Cost, e Guido Calabresi (Yale), com The Cost of Accidents, assim como Henry Manne, George Stigler, Armen Alchian, Steven Medema e Oliver Williamson (SZTAJN, 2005, p.74).
} 
considerações de eficácia ser a melhor para uma determinada coletividade. Isso porque Posner concebe as relações jurídicas desde uma perspectiva contratual, propondo que, mesmo em situações em que a relação de contratação não seja passível de ser aplicada (como, por exemplo, situações de responsabilidade civil que envolvam acidentes), se faça um juízo hipotético e se questione como os envolvidos teriam se comportado se tivessem a oportunidade de contratar. Posner sustenta, nessa lógica, que "os valores a serem maximizados são o produto social medido conforme a capacidade e a vontade de pagar das pessoas reveladas nas transações voluntárias", mesmo que para isso seja necessário considerar um contrato hipotético (MACKAAY e ROUSSEAU, 2015, p.12).

A Análise Econômica do Direito guarda, então, uma profunda relação com a ideia de eficiência. As normas jurídicas são pensadas para se tornarem cada vez mais eficientes, o que implica que sua formulação compreenda algum tipo de análise econômica que possibilite a maximização de resultados. O elemento econômico ganha centralidade na formulação das normas jurídicas porque parte-se do pressuposto que, se as pessoas agem racionalmente ${ }^{4}$, haverá uma melhor resposta a incentivos externos que sejam elaborados de forma a estimular comportamentos que correspondam a um sistema de prêmios e punições ${ }^{5}$. Assim, entendendo a legislação como um estímulo externo, a Análise Econômica do Direito prevê que o sistema será mais eficiente a medida que as normas positivadas forem mais aderentes às instituições sociais (SZTAJN, 2005, p.75).

A Escola de Chicago - corrente da Análise Econômica do Direito da qual Posner faz parte $^{6}$ - busca aplicar tanto conceitos econômicos quanto a econometria na quantificação dos efeitos das normas positivadas. Esse método é utilizado, inclusive, em áreas do Direito em que os efeitos patrimoniais das relações pessoais costumam ser considerados como

\footnotetext{
${ }^{4}$ Nas palavras de Posner (1986, p.3): "The task of economics, so defined, is to explore the implications of assuming that man is a rational maximizer of his ends in life, his satisfactions - what we shall call his 'self-interest'."

${ }^{5}$ Posner (1986, p.4) explica que: "The concept of man as a rational maximizer of his self-interest implies that people respond to incentives - that if a person's surroundings change in such a way that he could increase his satisfactions by altering his behavior, he will do so".

${ }^{6}$ Além da Escola de Chicago, são correntes da Análise Econômica do Direito a Escola de Yale, a Escola da Public Choice, a Escola da Economia Institucional e a Escola da Nova Economia Institucional (SZTAJN e ZYLBERSZTAJN, 2005, p.77).
} 
secundários, o que seria o caso do Direito de Família. Por exemplo, enquanto alguns juristas entendem que as regras relativas à adoção são esquemas puramente de solidariedade, Posner "considera possível a existência de mercado em que seriam negociados Direitos parentais". Em outras palavras, a Análise Econômica do Direito propõe a precificação até mesmo das relações de afeto, pois considera como valores ou preços a serem pagos não somente a expressão monetária, mas também a gratidão ou o poder (SZTAJN, 2005, p.79-80).

A teoria de Posner se configura, primordialmente, como pragmatista. Não admite que os métodos de investigação e decisão do Direito estejam associados a uma teoria moral. Posner critica os juristas que estabelecem uma aproximação entre filosofia do direito e filosofia moral, pois entende que os magistrados devem agir pragmaticamente, formulando suas respostas a partir das ciências sociais, do senso comum, dos valores pessoais e profissionais, da intuição e da opinião. Dessa forma, a Análise Econômica do Direito se aproxima muito mais de uma análise sociológica-descritiva do Direito e se coloca em oposição às matrizes que se propõe a pensar o Direito a partir de um referencial filosóficoreflexivo - tal como o faz Dworkin (ABBOUD e OLIVEIRA, 2015, p.150).

O rechaço de Posner às concepções filosóficas do Direito também se expressa na própria noção de pragmatismo adotada pelo autor. Ele critica o que denomina como "philosophical pragmatism" (pragmatismo filosófico), isto é, uma corrente de autores que se preocupa com conceitos, que problematiza a correspondência entre linguagem e realidade e que se propõe a refletir sobre a real pertinência das questões por eles debatidas. Posner, diferentemente, concebe o pragmatismo como uma ferramenta que serve para fundamentar decisões políticas a partir de fatos e consequências concretas. Ele define essa noção de pragmatismo como "pragmatic adjudication", a qual podemos qualificar, então, como uma abordagem pragmática antiteórica ${ }^{7}$ da decisão judicial que possui uma acentuada preocupação com as consequências dela decorrentes (POSNER, 1999, p.227).

Apesar de criticar o pragmatismo filosófico, Posner não o rejeita por completo. $\mathrm{Na}$ verdade, como mencionado anteriormente, o pragmatismo filosófico é um dos três pilares

\footnotetext{
${ }^{7}$ Sobre pragmatismo antiteórico ver: FELIPE, Bruno Farage da Costa. O pragmatismo antiteórico de Richard A. Posner e as respostas da teoria moral para a decisão judicial. 2015. $158 \mathrm{f}$. Dissertação (Mestrado em Direito) - Universidade do Estado do Rio de Janeiro, Rio de Janeiro, 2015.
} 
teóricos que permitiram o desenvolvimento da Análise Econômica do Direito. E Posner reconhece que há uma importante relação entre os dois tipos de pragmatismos que cumpre um papel central na formação de juízes menos dogmáticos e tendencialmente mais pragmatistas:

\begin{abstract}
Philosophical pragmatism and pragmatic adjudication are not completely unrelated. The tendency of most philosophical speculation — and it is what makes philosophy, despite its remoteness from quotidian concerns, a proper staple of college education in a liberal society - is to shake up a person's presuppositions. A judge or lawyer who reads philosophy or (more likely) is reminded of the reading he did as a student may feel the presuppositions that define his professional culture shift beneath him. Philosophy, especially the philosophy of pragmatism, incites doubt, and doubt incites inquiry, making a judge less of a dogmatic, more of a pragmatic or at least open-minded, adjudicator. (POSNER, 1999, p.227-228)
\end{abstract}

Uma das principais críticas que o pragmatismo recebe, segundo Posner, é a ausência de uma orientação moral. No entanto, o autor entende que essa recusa a uma teoria moral é justamente um dos principais passos para se caminhar em direção à reformulação da teoria jurídica e política. Posner sustenta que o pragmatismo serve para demonstrar a impossibilidade de se utilizar teorias abstratas para orientar e condicionar ações políticas e judiciais. Para ele, teorias que estabeleçam consensos morais e políticos não podem servir como limitantes para a ação política. Se aceitarmos que uma sociedade é moralmente heterogênea e que possui uma pluralidade de objetivos e preferências, então, defende Posner, concluímos que a ação política somente deve ser restringida por fatores psicológicos, profissionais e institucionais (POSNER, 2003, p.55-56).

Por outro lado, ainda que a "pragmatic adjudication" seja hostil à ideia de usar teorias morais e políticas para a tomada de decisões judiciais, essa abordagem não rejeita completamente o uso de teorias. Por ter uma orientação empirista, o pragmatismo posneriano é receptivo, por exemplo, a teorias que orientem a pesquisa empírica. Isso não significa, entretanto, que somente os fatos de cada caso sejam pertinentes. A abordagem judicial pragmática também considera como um fator relevante as consequências sistêmicas da decisão. Ainda assim, somente em situações excepcionais os impactos sistêmicos vão ser o principal fator decisório para um juiz pragmatista. As circunstâncias específicas do caso é que costumam determinar o processo decisório (POSNER, 2003, p.59). 
Dessa forma, o principal critério de uma decisão judicial pragmática é a razoabilidade. Isso significa sopesar não apenas as consequências específicas da decisão, mas também o conjunto de disposições legais, a pertinência de manter precedentes e diversas outras considerações que, para Posner, são impossíveis de serem enumeradas. Em síntese, o juiz pragmatista é aquele que coloca a experiência acima da lógica. E, justamente por isso, Posner entende que, apesar de colocar ênfase nas consequências, a "pragmatic adjudication" não é uma forma de consequencialismo. O juiz pragmatista, ao orientar sua decisão a partir da ideia de razoabilidade, não é obrigado a levar em consideração todas as possíveis consequências de suas decisões (POSNER, 2003, p.60-64).

Por fim, em relação especificamente aos precedentes, Posner (1999, p.241) explica que "pragmatist judges always try to do the best they can do for the present and the future, unchecked by any felt duty to secure consistency in principle with what other officials have done in the past". Portanto, a razoabilidade como critério orientador da decisão judicial pragmatista implica que o juiz não se sinta obrigado a manter uma coerência entre a sua decisão e casos anteriormente julgados. $\mathrm{Na}$ "pragmatic adjudication" o juiz somente decidirá de acordo com um ou mais precedentes se isso representar o melhor método para se produzir os melhores resultados para o futuro. Em outras palavras, a abordagem pragmática posneriana não concebe a adesão a precedentes como um dever ético, mas sim como uma necessidade justificada e voltada para o futuro (POSNER, 2003, p.60).

\section{O CASO DA MEDIDA CAUTELAR NA ADI 5.624 E OS ARGUMENTOS POLÍTICO-ECONÔMICOS DO STF}

A Ação Direta de Inconstitucionalidade 5.624/DF foi ajuizada pela Federação Nacional das Associações do Pessoal da Caixa Econômica Federal (FENAEE) e pela Confederação Nacional dos Trabalhadores do Ramo Financeiro (CONTRAF/CUT). Com pedido cautelar, a ação tinha como objeto a declaração de inconstitucionalidade do texto da Lei $\mathrm{n}^{\circ} 13.303$ de 2016. A lei atacada, conhecida como Lei das Estatais, foi promulgada com vistas a regulamentar o art. $173, \S 1^{\circ}, \mathrm{da} \mathrm{CF}^{8}$, dispositivo que trata do estatuto das empresas

\footnotetext{
8 “Art. 173. Ressalvados os casos previstos nesta Constituição, a exploração direta de atividade econômica pelo Estado só será permitida quando necessária aos imperativos da segurança nacional
} 
públicas, sociedades de economia mista e suas subsidiárias.

A Lei $n^{0} 13.303$ também foi impugnada por meio de outras três ADIs - 5.846/DF, 5.924/MG e 6.029/DF -, as quais foram distribuídas por dependência. O Min. Relator Ricardo Lewandowski determinou, então, o julgamento conjunto de todas as ações nos autos da ADI 5.624, tendo em vista que se encontrava em estágio mais avançado de julgamento em relação às demais, além de apresentar maior abrangência.

Em 27 de junho de 2018, a medida cautelar foi concedida em parte pelo Ministro Relator Ricardo Lewandowski, ad referendum do Plenário do STF. A decisão cautelar conferiu interpretação conforme à Constituição ao art. 29, caput, XVIII, da Lei ${ }^{0}$ 13.303/2016 ${ }^{9}$, nos seguintes termos: (i) sempre que se tratar de alienação de controle acionário, a venda de ações de empresas públicas, sociedades de economia mista ou de suas subsidiárias ou controladas exige prévia autorização legislativa; (ii) a licitação somente pode ser dispensada quando a venda de ações de empresas públicas, sociedades de economia mista ou de suas subsidiárias ou controladas não importem a perda de controle acionário.

O Plenário do STF, reunido para julgamento em 6 de junho de 2019, terminou por referendar apenas em parte a medida cautelar concedida pelo Ministro Relator. Diante de uma longa votação com muitas divergências de posicionamentos ${ }^{10}$, o Presidente Min. Dias Toffoli precisou costurar um voto médio para dar fim ao caso. A decisão final do Plenário resultou na seguinte redação:

No mérito, em razão de voto médio, referendar, em parte, a medida cautelar anteriormente parcialmente concedida pelo Ministro Ricardo Lewandowski (Relator), para conferir ao art. 29, caput, inc. XVIII, da Lei $n^{\circ} 13.303 / 2016$ interpretação conforme à Constituição Federal, nos seguintes termos: i) a alienação

ou a relevante interesse coletivo, conforme definidos em lei. $\S 1^{\circ} \mathrm{A}$ lei estabelecerá o estatuto jurídico da empresa pública, da sociedade de economia mista e de suas subsidiárias que explorem atividade econômica de produção ou comercialização de bens ou de prestação de serviços, dispondo sobre: (Redação dada pela Emenda Constitucional n 19, de 1998)."

9 “Art. 29. É dispensável a realização de licitação por empresas públicas e sociedades de economia mista: (...) XVIII - na compra e venda de ações, de títulos de crédito e de dívida e de bens que produzam ou comercializem".

${ }^{10}$ Em síntese, os Ministros Ricardo Lewandowski (Relator), Edson Fachin e Marco Aurélio votaram pelo referendo total da cautelar; os Ministros Cármen Lúcia, Rosa Weber, Gilmar Mendes e Dias Toffoli (Presidente) se manifestaram pelo referendo parcial; e os Ministros Alexandre de Moraes, Roberto Barroso, Luiz Fux e Celso de Mello decidiram não referendar a medida cautelar. 


\begin{abstract}
do controle acionário de empresas públicas e sociedades de economia mista exige autorização legislativa e licitação; e ii) a exigência de autorização legislativa, todavia, não se aplica à alienação do controle de suas subsidiárias e controladas. Nesse caso, a operação pode ser realizada sem a necessidade de licitação, desde que siga procedimentos que observem os princípios da administração pública inscritos no art. 37 da Constituição, respeitada, sempre, a exigência de necessária competitividade. (BRASIL, 2019, p.2)
\end{abstract}

Como visto, foi debatido em sede de cautelar especificamente o art. 29, caput, inc. XVIII da Lei $n^{0} 13.303 / 2016$, sendo a discussão focalizada em dois pontos centrais: (i) necessidade de autorização legislativa e (ii) de licitação para alienação do controle acionário de empresas públicas, sociedades de economia mista e de suas subsidiárias. De forma geral, os Ministros concordaram que a alienação do controle acionário das empresas públicas e sociedades de economia mista exigem tanto autorização legislativa quanto licitação. No entanto, divergiram amplamente sobre a aplicação dessas condicionantes à alienação do controle de suas subsidiárias e controladas.

A complexidade do caso sob análise se deve ao fato de envolver juízo de constitucionalidade sobre tema de grande controvérsia não somente jurídica, mas também político-econômica. Ainda que a decisão do STF esteja fundamentada em pressupostos estritamente jurídicos, seu teor impacta diretamente nos planos governamentais para exploração direta da atividade econômica pelo Estado. Tanto é assim que a mídia anunciou o resultado do julgamento como uma vitória para o governo Bolsonaro na flexibilização de regras para a comercialização de estatais (EXAME; G1; JOTA; JORNAL DO BRASIL, 2019).

Para além do controle de constitucionalidade, também questões político-econômicas permearam os votos dos Ministros. O trecho a seguir, retirado do voto do Min. Luiz Fux, ilustra bem a preocupação manifestada por alguns Ministros com as consequências, impactos ou repercussões do julgamento da Medida Cautelar na ADI 5.624:

O tema em análise traz consigo profundas repercussões político-econômicas. Não se pode perder de vista que a insegurança jurídica que hoje permeia a aplicação e higidez constitucional da Lei das Estatais pode obstaculizar o livre atuar dessas empresas no mercado, justamente num contexto de crise econômica que demanda maior confiabilidade e atratividade no proceder da Administração Pública. (...) Especificamente no que concerne ao objeto da liminar concedida nas ADIs em análise, vislumbram-se potenciais impactos nos planos de desinvestimento já em 
progresso, em detrimento do planejamento gerencial das estatais e das decisões institucionais aprovadas pelos respectivos conselhos de administração e/ou assembleia-geral de acionistas (BRASIL, 2019, p.174, grifos nossos).

No voto exarado pelo Min. Luís Roberto Barroso encontramos trecho em que o próprio magistrado explicita a utilização de argumentos pragmatistas. O Ministro sopesa circunstâncias políticas atreladas à atuação do Congresso Nacional para avaliar os impactos econômicos da decisão judicial sobre as atividades das empresas estatais e sociedades de economia mista. Veja-se:

\begin{abstract}
Ora, submeter ao regime das empresas privadas não pode - com respeito pelas compreensões diferentes - significar exigência de lei para vender ações, mesmo que signifique o controle, porque, pura e simplesmente, isso não se aplica na iniciativa privada. Imaginem - e aqui passando para o plano pragmático - o custo de transação que haveria se, a cada operação relevante de venda de ações de uma subsidiária de empresa estatal, precisasse ser obtida do Congresso Nacional uma autorização, sendo que o Congresso tem circunstâncias políticas que não correspondem às necessidades econômicas da empresa. Portanto, há uma total assimetria nessa relação e acho que uma não pode estar (BRASIL, 2019, p.110, grifos nossos).
\end{abstract}

Ainda em relação ao voto do Min. Barroso, destacamos a utilização de argumentos pragmático-empiristas. $\mathrm{O}$ trecho reproduzido a seguir demonstra que o magistrado fez uso de dados acerca de um caso específico - anúncio público da venda da $\mathrm{TAG}^{11}$ - para fundamentar seu posicionamento acerca da dispensabilidade de licitação no caso de alienação do controle acionário de subsidiárias de empresas públicas e sociedades e economia mista. Dito de outra maneira, o Ministro consubstanciou seu juízo de constitucionalidade acerca do art. 29, caput, inc. XVIII da Lei ${ }^{\circ}$ 13.303/2016 em fontes empíricas. Veja-se:

E verifiquei, Presidente, do material apresentado pela Petrobras, de indagações que eu mesmo formulei, que, após o anúncio público da venda da TAG, apareceram 87 empresas interessadas na aquisição. Dessas empresas que obtiveram as informações, 28 apresentaram propostas preliminares. E, depois, 3 grandes consórcios fizeram propostas finais, tendo vencido a proposta de $\mathrm{R} \$ 8,6$ bilhões, que era, embora não houvesse um preço mínimo especificado, superior à avaliação interna de R \$ 7,5 bilhões. (...) Portanto, considero que houve uma competição, que se realizou a melhor contratação que o mercado ofereceu no momento da venda.

\footnotetext{
${ }^{11}$ Transportadora Associada de Gás S.A.
} 
Logo, ainda que não se tenha seguido à risca a Lei ${ }^{0} 8.666$, a minha posição é a de que houve um certame competitivo, baseado em uma exceção prevista em lei e regulamentado de maneira satisfatória por um decreto (BRASIL, 2019, p.113).

Após a conclusão do voto do Min. Barroso, o Relator Min. Ricardo Lewandowski faz um esclarecimento que é acolhido pelo Presidente Min. Dias Toffoli. Ambos os magistrados referem que os argumentos utilizados pelo Min. Barroso sobre o caso da TAG e sua relação com o processo licitatório da Lei n ${ }^{\circ} 8.666$ não estão sob análise no julgamento da ADI 5.624. Ações de controle normativo abstrato como uma ADI não compreendem, pelo menos em tese, apreciação de casos específicos. Veja-se:

O SENHOR MINISTRO RICARDO LEWANDOWSKI (RELATOR) Presidente, pela ordem. (...) Louvo o Ministro Luís Roberto Barroso pelo excelente voto que traz ao Plenário para reflexão, mas apenas um esclarecimento. Em nenhum momento, em meu voto, eu disse que se deve aplicar a Lei 8.666, apenas um processo licitatório, seja aquele previsto na Lei 9.491/1997, seja o do Decreto 1.091/1994, e esta é uma questão que nós vamos ver depois, na reclamação.

O SENHOR MINISTRO DIAS TOFFOLI (PRESIDENTE): (...) É importante o esclarecimento do Relator. O caso específico da TAG, objeto da reclamação em que foi concedida liminar pelo Ministro Luiz Edson Fachin com base na cautelar que estamos discutindo, não está em julgamento nessas ações diretas, porque elas são ações de controle normativo abstrato (BRASIL, 2019, p.115).

Em resposta ao Presidente Min. Dias Toffoli, o Min. Barroso manifesta expressamente que está considerando as repercussões políticas da decisão ao fundamentar seu posicionamento. Veja-se:

\begin{abstract}
Eu acredito - se me permite só mais um brevíssimo comentário - que, no fundo, nós estamos travando um debate político disfarçado de discussão jurídica, que é a definição de qual deve ser o papel do Estado e quem deve deliberar sobre este papel no Brasil atual. Eu acho que é uma decisão do Executivo. Eu creio que há uma legislação que autoriza esse encaminhamento. E penso - esse já é um debate político - que nós vamos ter que superar esse fetiche do Estado protagonista de tudo e criar um ambiente com mais sociedade civil, mais livre iniciativa, mais movimentos sociais e menos Estado e governo, salvo para as redes de proteção social a quem precisa e a prestação de serviços públicos de qualidade. Mas esse é o debate ideológico subjacente (BRASIL, 2019, p.116, grifos nossos).
\end{abstract}

Por fim, destacamos trecho do voto do Min. Gilmar Mendes, em que o magistrado utiliza argumentos pragmatistas para fundamentar seu posicionamento acerca da possibilidade de flexibilização do princípio da licitação. Conforme passagem transcrita a 
seguir, o Ministro desenvolve raciocínio sobre as estratégias econômicas por trás do art. 29, inciso XVIII, da Lei n $^{0}$ 13.303/2016 para justificar a possibilidade de se dispensar a licitação no caso de alienação de ações de empresas públicas e sociedades e economia mista. Veja-se:

Também nesse contexto de transformações na política de desestatização, a Lei 13.303/2016 objetivou conferir tratamento diferenciado aos processos de desinvestimento de empresas estatais. A promulgação da norma teve como pano de fundo o diagnóstico de que a atuação dessas entidades deveria ser revista no cenário nacional, considerando o alto grau de endividamento dessas empresas $\mathrm{e}$, em muitos casos, o seu baixo nível de eficiência e competitividade. A norma impugnada na presente ADI deve ser interpretada considerando tal contexto. (...) Para dar maior celeridade e flexibilidade aos processos de desinvestimentos de empresas do estado foi prevista a fórmula de licitação dispensável contida no art. 29, inciso XVIII, da Lei 13.303/2016. (...) Conforme reporta a abalizada doutrina de Alexandre Santos de Aragão, o processo de desinvestimento de empresas estatais perpassa escolhas estratégicas que muitas vezes vão além do mero aspecto financeiro. Daí porque faria sentido admitir-se uma flexibilização do princípio da licitação nessas situações (BRASIL, 2019, p.208-209).

Através dos trechos transcritos vimos exemplos de argumentos pragmatistas políticoeconômicos utilizados para fundamentar os votos dos Ministros do Supremo Tribunal Federal. Como demonstrado, esses argumentos aparecem de diversas formas: impactos da decisão, fontes empíricas de fundamentação, debate político-ideológico subjacente ao caso, motivações estratégico-econômicas envolvidas. No tópico a seguir analisaremos como esses argumentos pragmatistas de cunho político-econômico representam uma ameaça ao papel de guardião da Constituição atribuído ao STF por nossa Magna Carta.

\section{O PAPEL DO PODER JUdiCIÁRIO NA DEFESA DA CONSTITUIÇÃo SEGUNDO A CRÍTICA HERMENÊUTICA DO DIREITO DE LENIO STRECK}

Ortodoxia constitucional talvez seja uma das expressões que melhor defina a postura adotada por Lenio Streck ao desenvolver a Crítica Hermenêutica do Direito. Streck entende que decisões judiciais não podem ser teleológicas, pois isso seria admitir que a atividade judicial deve ser exercida segundo a consciência do juiz, suas ideologias e interesses políticos envolvidos. Para Streck, o Direito é mais do que isso. Se compreendemos que Direito significa (ou, pelo menos, pretende ser significado de) garantia, então a decisão judicial deve ser tomada por princípios e não por políticas. Em outras palavras, os princípios 
constitucionais devem ser concebidos desde uma perspectiva deontológica, isto é, reconhecidos enquanto padrões normativos que fortalecem a autonomia do Direito (STRECK, 2015a, s.p.).

Em entrevista concedida a Pedro Canário sobre o caso Demóstenes, Streck explica as implicações de se defender que os tribunais devem decidir por raciocínios morais políticos (tese de que os princípios são teleológicos) ou por princípios (tese de que os princípios são deontológicos):

\begin{abstract}
Para entender a primeira tese (de que os princípios são teleológicos), é necessário entender exatamente a segunda concepção, que é a de que os princípios são deontológicos. Essa tese é sustentada, entre outros, por Jürgen Habermas. Ele sabe - pois concorda expressamente com Dworkin nesse ponto - que os princípios recebem sua carga deontológica em razão de sua manifestação histórico-cultural no seio de uma comunidade política. Vale dizer: não é uma regra que oferece um "teste de pedigree" que confere validade jurídica a um princípio, mas, sim, um modo específico de a comunidade política se conduzir. Trata-se de um padrão decisório que se constrói historicamente e que gera um dever de obediência nos momentos posteriores. Isto é, os princípios funcionam pelo código lícito-ilícito. Nessa perspectiva, princípios são normas stricto sensu. São um “dever ser”. Não são meramente conselhos ou mandados de otimização. Ou seja, princípios não são valores. Dizendo de outro modo: tratar princípios teleologicamente é submeter direitos e garantias a um cálculo de custo e benefício, dispensando a sua obrigatoriedade e condicionando-os a pontos de vista parciais. Consequentemente, se analisarmos o case [provas colhidas contra Demóstenes] em questão de forma "teleológica", corremos o risco de aceitar respostas finalísticas, onde "os fins buscados (acabar com a impunidade, eficácia no combate à corrupção)" podem justificar os meios (CANÁRIO, 2012, s.p.).
\end{abstract}

Compreender os princípios como deontológicos significa que os tribunais devem julgar por princípios e, se for o caso, devem decidir contramajoritariamente. Assim, considerando que a Constituição se configura como um remédio contra maiorias, seu sentido e sua razão de ser somente são respeitados se os princípios nela contidos forem concebidos deontologicamente. Decidir por políticas e não por princípios é colocar argumentos morais, políticos e econômicos acima da lei e da Constituição; é legitimar uma Teoria Política do Poder em detrimento de uma Teoria do Direito (STRECK, 2019b, s.p.).

A Crítica Hermenêutica do Direito problematiza tanto a teoria quanto a prática do Direito, assim como a distância existência entre esses dois campos. Segundo essa matriz, a teoria não nasce isolada num universo hermético, é inevitável que a teoria se alimente em 
alguma medida do mundo prático. A prática tão pouco existe por conta própria, muito pelo contrário, é articulada num universo interpretativo. A Crítica Hermenêutica busca demonstrar a importância da teoria para "organizar os sentidos" e "projetar um horizonte", compreendendo assim, que "a ambição descritiva não pode sufocar a prescritiva". Trata-se de construir as condições epistêmicas para que as decisões judiciais não sejam resultado de opiniões pessoais, influências políticas, econômicas ou midiáticas, mas, sim, fruto do respeito à normatividade da Constituição (STRECK, 2015b, s.p.).

Dizer que as decisões judiciais não devem ser tomadas a partir de fundamentos morais, políticos ou econômicos não é o mesmo que afirmar que o Direito está imune de elementos morais, políticos e econômicos. Muito pelo contrário. Somente podemos ter direitos assegurados "em um Estado em que os direitos são respeitados; e o fundamento para respeitá-los é, sim, moral”. Ao fim e ao cabo, o Direito nada mais é que o resultado daquilo que os integrantes de determinada comunidade política entendem como correto. Ele é a síntese das conflitividades morais, políticas e econômicas de determinada sociedade. Portanto, as discussões morais devem preceder o Direito. Quando o Direito está posto, está dada a síntese dessas conflitividades, o que significa que a moral não pode retornar para “corrigir quaisquer deficiências" do Direito (STRECK, 2014, s.p.).

Permitir que a moral interfira no Direito já posto significa romper com o sistema moral previamente concebido, sistema que garante que os direitos sejam respeitados. Em outras palavras, é justamente a incorporação da moral o que fundamenta os princípios orientadores da aplicação do Direito. No trecho a seguir, Streck define de forma precisa o que é o Direito e sua relação com a moral:

\begin{abstract}
Direito não é moral. Direito não é sociologia. Direito é um conceito interpretativo e é aquilo que é emanado pelas instituições jurídicas, sendo que as questões a ele relativas encontram, necessariamente, respostas nas Leis, nos princípios constitucionais, nos regulamentos e nos precedentes que tenham DNA constitucional, e não na vontade individual do aplicador. Ou seja, ele possui, sim, elementos (fortes) decorrentes de análises sociológicas, morais etc. Só que estas, depois que o Direito está posto - nesta nova perspectiva (paradigma do Estado Democrático de Direito) -, não podem vir a corrigi-lo (STRECK, 2018, p. 1).
\end{abstract}

A partir de um olhar dworkiniano, Streck explica que há uma correlação entre política 
- entendida como poder administrativo - e o Direito. Por um lado, o Direito presta legitimidade à política; por outro, a política é que garante coercitividade ao Direito. Cabe ao Direito restringir a política em defesa dos direitos das minorias, estabelecendo o limite das decisões contra majoritárias. Dessa forma, se considerado como um empreendimento público, o Direito é essencialmente político. No entanto, no que concerne ao discurso judicial, cumpre lembrar que não devem ser debatidas questões políticas em sentido estrito, isto é, aquelas que se manifestam a partir de raciocínios teleológicos. No momento da aplicação e concretização do Direito, como já dito anteriormente, devem prevalecer as questões de princípio - deontológicas - e não de política - teleológicas (STRECK, 2012, s.p.).

Diante de todo o exposto, podemos afirmar que, quando os Ministros do STF utilizam argumentos pragmatistas de cunho político-econômico, como no caso da ADI 5.624 anteriormente analisado, estão julgando a partir de argumentos de política. Isso significa que os Ministros estão utilizando juízos teleológicos para fundamentar suas interpretações da Constituição. No momento em que o pragmatismo posneriano rejeita o uso de teorias morais na orientação do processo de tomada de decisão judicial, ele está abrindo espaço para que a moral, através da subjetividade do juiz, venha determinar o conteúdo do Direito já posto.

Conforme definições utilizadas por Streck, o pragmatismo jurídico é uma teoria "anti-hermenêutica" que termina por colocar o Direito em "constante estado de exceção hermenêutico". No pragmatismo, a produção democrática do Direito fica em segundo plano, cabendo ao juiz tomar a decisão "cujas consequências estiverem mais ajustadas às necessidades humanas e sociais". A lei se configura apenas como mais um elemento dentre os vários recursos, incluídos também aqueles extrajurídicos, que estão à disposição do juiz para interpretar a lei com vistas a atender as necessidades sociais presentes e futuras. A decisão pragmatista, portanto, não tem um compromisso com aquilo que foi decidido no passado ou com a manutenção da integridade e da coerência lógica do sistema jurídico (STRECK, 2017, p.225).

Importante esclarecer que quando Streck fala em integridade e coerência do Direito, ele está fazendo referência a Dworkin. O jusfilósofo estadunidense compreende o Direito como uma atividade que permite, diante da divergência, encontrar a melhor interpretação 
possível para determinada controvérsia e, assim, chegar-se a uma resposta correta. Em outras palavras, resolve-se a divergência a partir da melhor justificação, concebida como a interpretação capaz de articular coerentemente todos os elementos que compõe o Direito, como regras, princípios, precedentes etc. (DWORKIN, 2001, p.119-123).

Nessa perspectiva, a coerência e a integridade são os elementos que, no caso da decisão judicial, vão assegurar que casos diferentes sejam julgados com igual consideração. Enquanto a coerência determina que o julgamento de casos semelhantes deve guardar uma consistência lógica entre si, a integridade se configura como uma garantia contra arbitrariedades interpretativas na medida em que coíbe o emprego de dois pesos e duas medidas na decisão judicial. A Crítica Hermenêutica do Direito utiliza e amplia essa tese de Dworkin, defendendo que "o Direito não pode ser o campo das incertezas (dos relativismos), e que nele (e em toda a nossa experiência) há sempre algo anterior que nos vincula, direciona nosso olhar" (STRECK, 2017, p.34-35).

Diante do exposto, a integridade e a coerência são os elementos que nos permitem falar em responsabilidade política do julgador na efetivação da democracia. As posturas pragmatistas, ao darem enfoque para a vontade/poder do juiz, promovem a instrumentalização do Direito e afastam as perspectivas de integridade e coerência. Assim, decisões judiciais tomadas com base em argumentos pragmatistas de cunho políticoeconômico acabam enfraquecendo a autonomia do Direito. Para Streck, a Análise Econômica do Direito "se insere no conjunto de discursos predadores do Direito (e de sua autonomia), ao lado da política e da moral" (STRECK, 2018, p.107).

\section{CONSIDERAÇÕES FINAIS}

A partir de reflexão gerada pela ideia de predadores do Direito - cunhada por Streck -, o presente artigo buscou investigar as ameaças que interesses econômicos podem representar à tomada de decisões judiciais dentro de um Estado Democrático de Direito constituído sob as bases de uma Constituição. Num primeiro momento, discorremos sobre a Análise Econômica do Direito e, em seguida, analisamos os argumentos pragmatistas de cunho político-econômico que constituíram a fundamentação dos votos dos Ministros do STF exarados no julgamento da ADI 5.624. 
Com base na Crítica Hermenêutica do Direito de Streck, concluímos que a preservação do Estado Democrático de Direito exige reconhecer, antes de tudo, que o Direito está fundado em uma Constituição compromissória que consagra textualmente a cooriginariedade entre Direito e Moral. Isso significa que as decisões judiciais devem se dar por princípio e não por políticas, isto é, a interpretação do Direito deve se dar deontologicamente. As posturas pragmatistas em geral, e a Análise Econômica do Direito em específico, representam a utilização de argumentos teleológicos que, quando aplicados às decisões judiciais, enfraquecem a autonomia do Direito. Os interesses econômicos põem em risco, portanto, o compromisso da decisão judicial com a manutenção da integridade e da coerência que asseguram a responsabilidade política do julgador na efetivação da democracia.

\section{REFERÊNCIAS}

BRASIL. Lei $\mathbf{n}^{\mathbf{0}}$ 13.303, de 30 de junho de 2016. Dispõe sobre o estatuto jurídico da empresa pública, da sociedade de economia mista e de suas subsidiárias, no âmbito da União, dos Estados, do Distrito Federal e dos Municípios. Disponível em: http://www.planalto.gov.br/ccivil_03/_ato2015-2018/2016/lei/113303.htm. Acesso em: 03 fev. 2020.

BRASIL. Supremo Tribunal Federal. Referendo na Medida Cautelar na Ação Direta de Inconstitucionalidade 5.624 - Distrito Federal. Reqte(s): Federação Nacional das Associações do Pessoal da Caixa Econômica Federal (FENAEE) e Confederação Nacional dos Trabalhadores do Ramo Financeiro (CONTRAF/CUT). Intdo(a/s): Presidente da República e Congresso Nacional. Relator: Min. Ricardo Lewandowski. Brasília, 6 de junho de 2019. Disponível em: http://portal.stf.jus.br/processos/detalhe.asp?incidente=5093069. Acesso em: 03 fev. 2020.

CANÁRIO, Pedro. "Direito não pode ser corrigido por valores morais". Consultor Jurídico, 02 abri. 2012. Disponível em: https://www.conjur.com.br/2012-abr-02/valoresmorais-nao-podem-nortear-principios-juridicos-lenio-streck. Acesso em: 05 fev. 2020.

DWORKIN, Ronald. A matter of principle. New York: Oxford University Press, 2001.

EXAME: STF permite venda de subsidiárias de estatais sem aval do Congresso. Brasília, 06 jun. 2019. Disponível em: https://exame.abril.com.br/economia/stf-permite-venda-desubsidiarias-de-estatais-sem-aval-do-congresso/. Acesso em: 03 fev. 2020.

G1: STF proíbe privatização de estatais sem aval do Congresso, mas permite venda de 
subsidiárias. Brasília, 06 jun. 2019. Disponível em: https://g1.globo.com/politica/noticia/2019/06/06/stf-julgamento-privatizacaoestatais.ghtml. Acesso em: 03 fev. 2020.

HOLMES JR., Oliver Wendell. The path of the law (Apêndice). In: BURTON, Steven J. (Editor). The Path of the Law and its influence: the legacy of Oliver Wendell Holmes Jr. Cambridge: Cambridge University Press, 2007.

JOTA: Os julgamentos mais importantes do STF em 2019. Brasília, 24 dez. 2019. Disponível em: https:/www.jota.info/stf/do-supremo/os-julgamentos-mais-importantes-dostf-em-2019-24122019. Acesso em: 03 fev. 2020.

JORNAL DO BRASIL: STF está em sintonia com o governo, diz Bolsonaro sobre privatização de estatais. Rio de Janeiro, 07 jun. 2019. Disponível em: https://www.jb.com.br/pais/2019/06/1003702-stf-esta-em-sintonia-com-o-governo--dizbolsonaro-sobre-privatizacao-de-estatais.html. Acesso em: 03 fev. 2020.

MACKAAY, Ejan; ROUSSEAU, Stéphane. Análise Econômica do Direito. Tradução Rachel Sztajn. 2. ed. São Paulo: Atlas, 2015.

MARRAFON, Marco Aurélio. Dworkin contra o pragmatismo de Posner na decisão judicial. Consultor Jurídico, 23 fev. 2015. Disponível em: https://www.conjur.com.br/2015-fev23/constituicao-poder-dworkin-pragmatismo-posner-decisao-judicial. Acesso em: 05 fev. 2020 .

MARTINS, José Eduardo F. A. Análise Econômica do Direito é instrumento de Justiça social. Consultor Jurídico, 10 jul. 2017. Disponível em: https://www.conjur.com.br/2017jul-10/opiniao-analise-economica-direito-meio-justica-social. Acesso em: 04 fev. 2020.

MILLARD, Eric; HEINEN, Luana R. A Análise Econômica do Direito: um olhar empirista crítico. Economic Analysis of Law Review, v.9, n.1, p.277-284, jan.-abr. 2018.

POSNER, Richard A. Economic Analysis of Law. 3. ed. Boston: Little Brown and Cy, 1986.

POSNER, Richard A. Law, Pragmatism, and Democracy. Cambridge: Harvard University Press, 2003.

POSNER, Richard A. The Problematics of Moral and Legal Theory. Cambridge: Harvard University Press, 1999.

RODAS, Sérgio. Para investigar epidemia que assola o Direito, Lenio traça 6 modelos de professor. Consultor Jurídico, 22 jun. 2019. Disponível em: https://www.conjur.com.br/2019-jun-22/lenio-traca-modelos-professor-investigarepidemia-direito. Acesso em: 05 fev. 2020. 
SZTAJN, Rachel. Law and Economics. In: SZTAJN, Rachel; ZYLBERSZTAJN, Décio (Coord.), Direito e Economia. Rio de Janeiro: Elsevier, 2005.

STRECK, Lenio L. Quando o Direito só serve para dizer o que é "feio" fazer. Consultor Jurídico, 05 jul. 2012. Disponível em: https://www.conjur.com.br/2012-jul-05/sensoincomum-quando-direito-serve-dizer-feio. Acesso em: 05 fev. 2020.

STRECK, Lenio L. O Direito está nas ruas, na lei ou na consciência? Consultor Jurídico, 26 set. 2013. Disponível em: https://www.conjur.com.br/2013-set-26/senso-incomumdireito-ruas-lei-ou-consciencia. Acesso em: 05 fev. 2020

STRECK, Lenio L. "Salvo pela lei, morto pela moral": como devem decidir os juízes? Consultor Jurídico, 16 out. 2014. Disponível em: https://www.conjur.com.br/2014-out16/senso-incomum-salvo-lei-morto-moral-decidir-juizes. Acesso em: 05 fev. 2020.

STRECK, Lenio L. O que é decidir por princípios? A diferença entre a vida e a morte. Consultor Jurídico, 06 ago. 2015a. Disponível em: https://www.conjur.com.br/2015-ago06/senso-incomum-decidir-principios-diferenca-entre-vida-morte. Acesso em: 05 fev. 2020.

STRECK, Lenio L. O juiz que fez a coisa certa! Mídia e moral não são fontes de Direito. Consultor Jurídico, 10 nov. 2015b. Disponível em: https://www.conjur.com.br/2015-nov19/senso-incomum-juiz-fez-coisa-certa-midia-moral-nao-sao-fontes-direito. Acesso em: 05 fev. 2020 .

STRECK, Lenio L. Dicionário de Hermenêutica: quarenta temas fundamentais da teoria do Direito à luz da teoria crítica do Direito. Belo Horizonte (MG): Letramento, 2017.

STRECK, Lenio L. 30 Anos da CF em 30 Julgamentos: uma radiografia do STF. Rio de Janeiro: Forense, 2018.

STRECK, Lenio L. Ideologizar o Direito dá nisso: aplicar o óbvio da lei vira absurdo. Consultor Jurídico, 21 mar. 2019a. Disponível em: https:/www.conjur.com.br/2019-mar21/senso-incomum-ideologizar-direito-nisso-aplicar-obvio-lei-vira-absurdo. Acesso em: 05 fev. 2020.

STRECK, Lenio L. Apropriação moral e política do Direito degrada o Estado de Direito. Consultor Jurídico. 26 dez. 2019b. Disponível em: https://www.conjur.com.br/2019-dez26/senso-incomum-apropriacao-moral-politica-direito-degrada-estado-direito. Acesso em: 05 fev. 2020. 